\title{
Development of urban infrastructure socially significant elements classification for ensuring their autonomy
}

\author{
Liubov Shilova* \\ Moscow State University of Civil Engineering, 129337, Moscow, Russian Federation
}

\begin{abstract}
The paper presents the results of the urban infrastructure properties of socially significant elements study to ensure their autonomy for creating a safe and comfortable living environment for the population during the transition to Industry 4.0. A refined formulation of the urban infra-structure elements autonomy concept is given. The urban infrastructure elements classification is developed using a hierarchical classification method. It is proposed to assign a cipher to each construction object included in urban infrastructure, which will correspond to a set of autonomy parameters indicators. This cipher will contain the information about the type and kind of a construction object, its purpose, as well as the hazard class and their negative impact on the environment. In addition, this cipher can help to deter-mine a set of parameters that characterize the construction object autonomy state.
\end{abstract}

\section{Introduction}

The term ecosystem in nature has an established meaning, but in the information technology (IT) industry it is new and there are several options to explain this approach. In this article the ecosystem in IT is considered as an end-to-end data trans-fer and communication of all services. An example of such projects is Apple Corporation where the devices are linked to each other by a common IT platform, services, etc.

The city, which consists of the elements (construction objects), united by the complex interconnected service structures and fulfilling a single purpose, is a complex, open system that is influenced by both internal and external factors. At the same time, in the field of urban infrastructure development, the attempts to transfer this system into an ecosystem are also being made. An example of such attempts is the process of developing the concept of a smart city, which today includes the following main concepts:

- Smart care;

- Smart energy;

- Smart society;

- Smart office;

* Corresponding author: ShilovaLA@mgsu.ru 
- Smart mobility;

- Smart Space.

The term Smart City was officially announced in 1994 and assumed the active introduction of information and communication technologies into the urban infrastructure. It should be noted that since the introduction of this concept, the level of information and communication technologies development has significantly increased and modernized the concept of a smart city, integrating all the best world practices into it.

The analysis of publication activity in the Scopus database indicates that interest in research of the smart city concept development originated at the end of the last century. In the period from 1971 to 2000 there are 126 publications in the specified knowledge base for the keyword "smart city". Since 2001, the number of publications started increasing annually, however, the greatest growth was noted in 2013, when the number of publications almost doubled: from 476 publications in 2012 to 805 publications in 2013. The dynamics of changes in the number of publications for the keyword "Smart city" in the Scopus knowledge base from 2011 to 2020 are presented in the Fig.1.

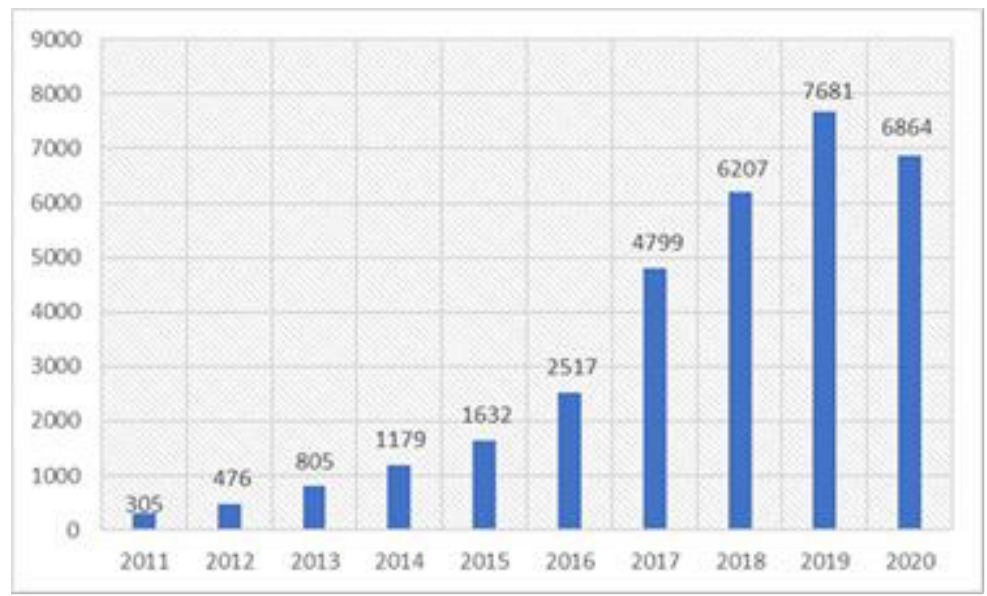

Fig. 1. Publication activity of the researchers for the keyword "smart city" according to the Scopus database

The decrease of the publications number in 2020 is justified by the fact that papers and articles from not all scientific journals have been indexed in Scopus at the time of sampling.

In the period from 2011 to 2020, 32,465 publications were recorded by the keyword "smart city". The largest number of publications relates to the field of knowledge computer science (31\%), engineering - 19\% and social sciences - $11.5 \%$.

The largest number of publications belongs to the authors from China - 6119, in the second place is the United States - 3950 publications, in the third - India - 3253.

The analysis of a number of publications participating in the sample showed that a smart city includes the active use of information and communication technologies and is aimed at meeting the needs of its residents, providing them with a safe and comfortable living environment [1-16].

On the other hand, humanity is in the process of transitioning to Industry 4.0, within which the massive introductions of cyber-physical systems in production, the Internet of Things, 3D printing, etc. are predicted. That is why these technologies became the subject of a large number of scientific publications [6-16] confirming the digital transformation of modern society.

Despite the rapid development of science and technology, it is necessary to understand that the introduction of such technologies is associated with the solution of a number of 
scientific problems that will be caused by the fact that people, processes and technologies are becoming the main asset of a smart city. At the same time, it is assumed that the smart city concept implementation will improve the management system and interaction between the state and society, improve the quality and efficiency of city services and provide a comfortable living environment for the population.

According to the smart city concept three fundamental development factors are singled:

- Intellectualization;

- Manufacturability;

- Environmental friendliness, including safety, energy intensity and comfort of living conditions.

Smart city technologies are usually introduced into the existing urban infrastructure, and now a technological process is constantly taking place in buildings and structures, which can lead to the emergence of new previously unexplored sources of emergency situations, and the risks associated with them, but also these technologies will make it possible to timely identify and prevent any emergency.

In the presented article, an attempt to concretize the definition of a socially significant element of urban infrastructure, to form a definition of the autonomy of a socially significant element of urban infrastructure in the light of the transition to Industry 4.0 from the point of safety in emergencies is made. A classification of the socially significant elements of urban infrastructure is proposed to ensure their autonomy.

\section{Methods}

The complex of interconnected service structures that form the basis of the functioning of the city as a system is commonly called infrastructure. Currently, there are a lot of approaches to the urban infrastructure classification [17-18]. However, the presented classifications do not consider the importance of the object in terms of ensuring a safe and comfortable living environment and the level of its technological development in the event of an emergency.

An analysis of the classification types was carried out to select a research method. The main advantages and disadvantages of both systems are presented in Table 1.

Table 1. The main advantages and disadvantages of information classification methods [19]

\begin{tabular}{|c|c|c|}
\hline & Hierarchical classification method & Faceted classification method \\
\hline Description & $\begin{array}{l}\text { Each level of classification is a set of } \\
\text { objects similar in one attribute. } \\
\text { Differences between objects at } \\
\text { different stages of classification are } \\
\text { recorded. Class relationships form a } \\
\text { hierarchical classification structure. }\end{array}$ & $\begin{array}{l}\text { It is a set, the elements of which are } \\
\text { sets. It is a collection of several } \\
\text { independent classifications carried out } \\
\text { simultaneously on different grounds. } \\
\text { Each facet characterizes one feature of } \\
\text { the distributed set. }\end{array}$ \\
\hline Advantages & $\begin{array}{l}\text { - Ability to highlight the } \\
\text { commonality and similarity of the } \\
\text { objects' features at the same and } \\
\text { different stages; } \\
\text { - high information saturation. }\end{array}$ & $\begin{array}{l}\text { - Flexibility and ease of use of the } \\
\text { system; } \\
\text { - Possibility to cover or limit all } \\
\text { classification objects characteristics. }\end{array}$ \\
\hline $\begin{array}{c}\text { Disadvan- } \\
\text { tages }\end{array}$ & $\begin{array}{l}\text { - Informational insufficiency, } \\
\text { incomplete coverage of objects } \\
\text { and/or signs in some cases }\end{array}$ & $\begin{array}{l}\text { - Groupings are not subordinate to each } \\
\text { other; } \\
\text { - Difficulty in determining the weight } \\
\text { of the object's classified } \\
\text { characteristics. } \\
\text { - Inability to highlight the commonality } \\
\text { and differences between the objects in }\end{array}$ \\
\hline
\end{tabular}


different classification groupings

The paper uses a hierarchical classification method because it is assumed that the set is sequentially divided into the subsets with interrelated subordination to high-light subordination. The objects at each stage of classification are grouped according to one classification criterion.

\section{Results and discussions}

\subsection{Generalized classification of urban infrastructure elements}

Urban infrastructure is a complex of engineering and architectural objects focused on ensuring the life of the city and its population. Thus, the urban infrastructure consists of the elements and can be considered as a system fulfilling a single purpose. Elements of urban infrastructure have different purposes and include cultural heritage sites, industrial facilities, residential areas, etc.

Within the framework of the presented studies, the object of the study is the socially significant elements of urban infrastructure, under which the life support objects are accepted in the work.

A socially significant object is an object necessary for the urban population life support. An example of such facilities can be: educational organizations, medical institutions, facilities used to organize first aid, ambulance and emergency outpatient, inpatient medical care, communal infrastructure facilities related to life support systems, including water and heating facilities, gas and power supply, sewerage, wastewater treatment, treatment, disposal, neutralization and disposal of solid municipal waste, objects designed to illuminate the territories of urban and rural settlements, objects intended for landscaping. This definition is taken from several normative documents of European countries and scientific publications of Russian and foreign authors.

From the presented definition, it is accepted that socially significant objects can be life support objects or can be attributed to the other construction objects (for example, cultural heritage objects), this criterion will serve as the basis for identifying the first classification level (Fig. 2).

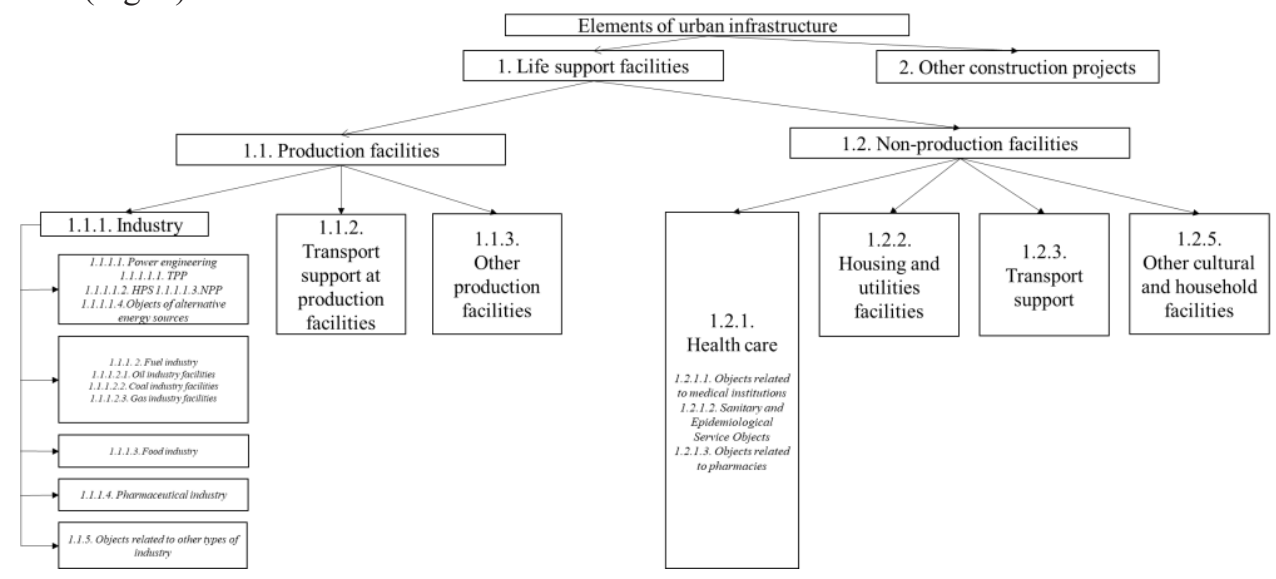

Fig. 2. Generalized classification of urban infrastructure elements

According to their functional purpose life support facilities are divided into two groups (the second stage of classification). These are the objects for production and non- 
production purposes. The first group of objects includes production facilities that are united by the function of producing resources or providing services.

The second group also contains a lot of objects that do not produce anything but are intended to serve the population.

Domestic and foreign regulatory legal acts contain different approaches to the classification of categories and classes of objects hazard. For example, in Belgium, dangerous objects are classified by type of activity, and in Greece by type of hazard. "In most countries (USA, Germany, Netherlands, Norway, Great Britain, France) the industrial facilities are classified according to the presence of hazardous substances at the facility. This approach is laid down in the Seveso Directive [20] (on the severe accidents prevention) and the Convention on the Transboundary Effects of Industrial Accidents" [21]. Hazardous substances and their threshold values for a specific object are standardized by legal documents and will not be considered in the work. Based on the analysis of existing experience, it is proposed to divide the objects depending on the severity of probable accidents and their elimination.

The classification of emergency situations depending on the severity is shown in Fig. 3.

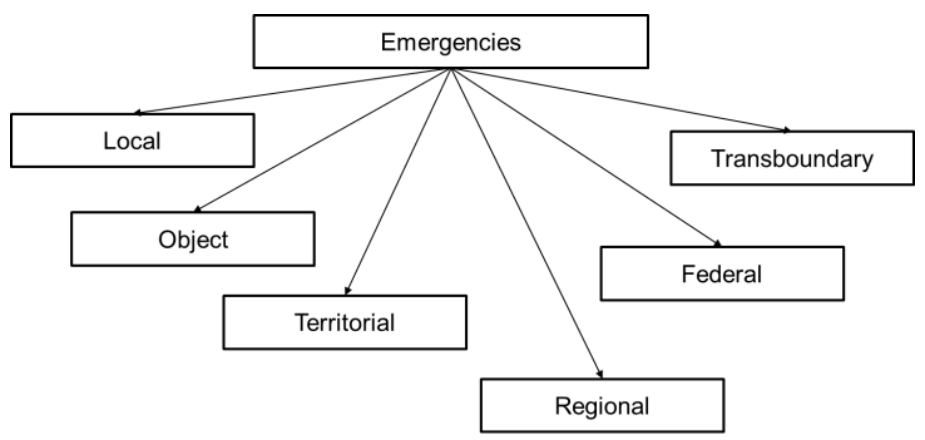

Fig. 3. Classification of emergency situations by severity

Based on the presented classification, approved by the regulatory documents, 4 classes of objects are distinguished:

The $1^{\text {st }}$ Class - facilities where emergency situations can cause emergency situations of a federal or transboundary scale;

The $2^{\text {nd }}$ Class - facilities where emergency situations can cause emergency situations of an interregional or regional scale;

The $3^{\text {rd }}$ Class - facilities where emergency situations can cause emergency situations of a territorial scale;

The $4^{\text {th }}$ Class - facilities where emergency situations can cause emergencies of a local or object scale.

Another important factor that needs to be paid attention to in terms of ensuring environmental safety is taking into account the impact of these facilities on the environment. In this regard, the objects are assigned a category that characterizes their negative impact on the environment (NIE). These 4 categories are allocated:

I Category - facilities that provide significant impact on the environment;

II category - facilities that provide moderate environmental impact on the environment;

III category - facilities that provide insignificant impact on the environment;

IV category - facilities that provide minimal impact on the environment.

In accordance with the described approach, all possible options for infrastructure facilities in terms of the ratio of the hazard class and their NIE are presented in Table 2. 
Table 2. Variants of infrastructure facilities by the ratio of hazard class and their impact on the environment

\begin{tabular}{|l|c|c|c|c|}
\hline $\begin{array}{c}\text { The category } \\
\text { of NIE } \\
\text { Hazard classes }\end{array}$ & I category & II category & III category & IV category \\
\hline The $1^{\text {st }}$ Class & 11 & 12 & 13 & 14 \\
\hline The $2^{\text {nd }}$ Class & 21 & 22 & 23 & 24 \\
\hline The $3^{\text {rd }}$ Class & 31 & 32 & 33 & 34 \\
\hline The $4^{\text {th }}$ Class & 41 & 42 & 43 & 44 \\
\hline
\end{tabular}

Each object will be characterized by a two-digit number, where tens is the class, and the number of ones is the category. Thus, each object can be described in the form of a cipher (Fig.4).

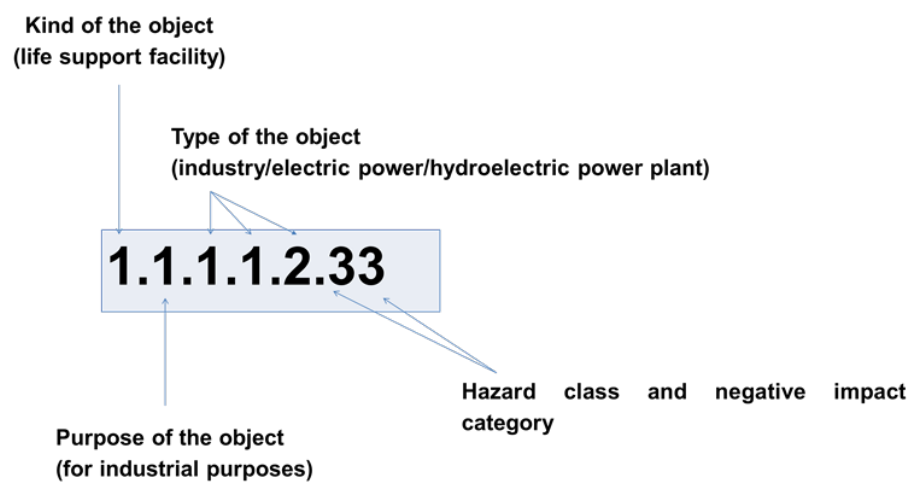

Fig. 4. An example of a life support facility cipher, taking into account the developed classification

\subsection{Approach to assessing the autonomy of urban infrastructure elements}

In the [22], based on the research carried out by the author, it is determined that the autonomy of an element of urban infrastructure is the ability of a construction object to fulfil its target function during the design life without external intervention in the emergency event. It was concluded that autonomy is a complex property that includes three indexes: reliability, sustainability and technogenic security. The reliability of the construction object includes the parameters $\left(r_{1}, r_{2}, r_{3}, \ldots, r_{m}\right)$; the sustainability of the construction object includes the parameters $\left(t_{1}, t_{2}, t_{3}, \ldots t_{m}\right)$; and natural and technogenic security can be described through the parameters $\left(s_{1}, s_{2}, s_{3}, \ldots s_{m}\right)$.

Thus, the autonomy of a building object can be represented in the form of a states' matrix:

$$
A_{n}=\left[\begin{array}{llll}
r_{n 1} & r_{n 2} & r_{n 3} \ldots r_{n m} \\
t_{n 1} & t_{n 2} & t_{n 3} \ldots t_{n m} \\
s_{n 1} & S_{n 2} & S_{n 3} \ldots s_{n m}
\end{array}\right]
$$

At the same time, under the object, depending on the system under consideration, it is necessary to take a complex of technologically and technically interconnected buildings, constructions, structures and systems, or a separate building and structure located on a separate territory (water area).

The set of these parameters (Fig. 5) will depend on the type of the object under consideration, determined based on the presented classification in accordance with the 
obtained cipher (Fig. 4), which describes the object. For convenience, the number of parameters will be assumed to be the same for each object, however, those parameters that are not relevant for the considered object will be assumed to be zero.

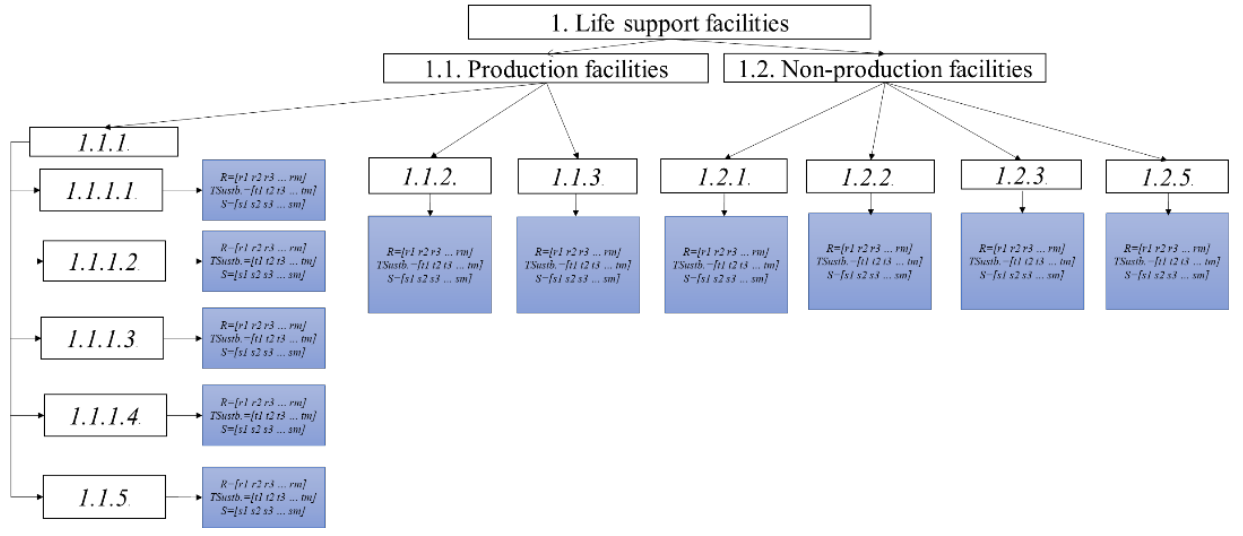

Fig. 5. The schematic representation of the relationship between the object type and its autonomy parameters

For each parameter there are the standard (calculated) values, and there are the actual values, the difference of these values will characterize the autonomy level of the object. The calculation method is presented in [22].

\section{Conclusion}

The risk concept is inherent in both safety and reliability and stability of complex building systems for various purposes and is changed depending on the tasks assigned to the researcher. In some reports presented at international conferences and seminars, the boundaries of these concepts are completely confused.

At the same time, the large-scale introduction of new technologies in the context of the transition to Industry 4.0 leads to the fact that processes, including technological ones, constantly occur in buildings and structures, which can lead to the emergence of new previously unexplored sources of emergency situations, and the risks associated with them.

However, it is necessary to understand that these technologies also provide significant advantages: for example, timely collection and processing of data that allows the calculations on the current state of the construction site.

Further studies are devoted to the objects' autonomy parameters indicators experimental determination issues (filled cells in Fig. 5) and their standard values depending on their type, as well as (the level of influence (weight) of these indicators' coefficients on the state of the object under consideration.

\section{References}

1. H. Li, M. Tao, Z. Zuo, Fres. Environ. Bul. 29 (12), 10915-10923 (2021).

2. S.A. Chun, D. Kim, J.-S. Cho, (...), S. Shin, D. Jun, Intern. Jour. of E-Plan. Res. 10 (3), 50-69 (2021).

3. A.P.P. Kasznar, A.W.A. Hammad, M. Najjar, (...), C.A. Pereira Soares, A.N. Haddad, Buildings 11 (2), 73 (2021).

4. R.M. Wang, W. Tian, Y. Cao, M.F. Yan, J. Gao, Applied Mechanics and Materials 448-453, 4134-4139 (2014). 
5. Y.Q. Zhu, J. Zuo, Adv. Mat. Res. 838-841, 3054-3059 (2014).

6. Y. Zhang, P. Geng, C.B. Sivaparthipan, B.A. Muthu, Sust. Ener. Tech. and Asses. 45, 100986 (2021).

7. S. Wang, F. Zhang, T. Qin, IOP Conf. Ser.: Ear. and Env. Sci. 1802 (4), 042045 (2021).

8. X. Shi, B. Wang, E3S Web of Con. 236, 04031 (2021).

9. D. Bin, Z. Ling, H. Yingqi, (...), Y. Zhenhao, Z. Jun, Jour. of Phy.: Con. Ser. 1738 (1), 012048 (2021).

10. Q. Liu, Adv. in Int. Sys. and Com. 1283, 68-73 (2021).

11. Z. Ge, Y. Hu, Adv. in Int. Sys. and Com. 1244 AISC 619-624 (2021).

12. G. Guo, L. Pang, Adv.in Int. Sys. and Com. 1234 AISC 212-217 (2021).

13. S. Li, Z. Jiang, J. Zhang, Adv. in Int. Sys. and Com. 1303, 1523-1528 (2021).

14. S. Yamamura, L. Fan, Y. Suzuki, Proc. Eng. 180, 1462-1472 (2017).

15. S.R. Vijayalakshmi, S. Muruganand, Int. Jour. of Con. The. and App. 9 (13), 62616265 (2016).

16. Y. Pan, Y. Tian, X. Liu, D. Gu, G. Hua, Eng. 2 (2), 171-178 (2016).

17. D. Paryigin, A. Aleshkevich, N. Sadovnikova, A. Zuev, Sys. Of Con., Com. And Sec. 2, 73-100 (2020).

18. P. Shvalov Soc. Eco. And Hum. Jou. Kra. GAU 1, 56-63 (2015).

19. A. Bezrukov, V. Gusyatnikov, M. Zhilina Bul. SGTU 4 (73), 151-155 (2013).

20. Directive 2012/18/EU of the European parliament and of the council

21. A. Kozlutin, Consideration of industrial safety factors in the feasibility study of thermal power facilities of enterprises (Moscow, 1998).

22. L. A. Shilova, IOP Conf. Ser.: Mater. Sci. Eng. 1015, 012090 (2021). 